\title{
Özgün araştırma makalesi Periapikal sağlık üzerine koronal restorasyonun kalitesine karşı kök kanal tedavisinin kalitesinin etkisi: sistematik derleme ve meta-analiz
}

\author{
Elif Bahar Çakıcı (iD), Fatih Çakıcı (iD * \\ Endodonti Anabilim Dalı, Diş Hekimliği Fakültesi, \\ Ordu Üniversitesi, Ordu, Türkiye
}

\section{ÖzeT}

AmAÇ: Bu çalışmanın amacı, periapikal sağlık üzerine kök kanal dolgusunun kalitesine karşı koronal restorasyonun kalitesinin etkilerini karşılaştırmaktır.

Gereç Ve Yöntem: Literatür taraması "endodontics", "periapical index", "periapical status", "quality of root canal treatment", "root treatment", "root canal treatment", "coronal restoration", "quality of root canal treatment", "cone beam computed tomography" ve "restoration" arama terimleri kullanılarak yapıldı. Kök kanal dolgusunun ve koronal restorasyonun kalitesinin periapikal dokulara etkisini değerlendiren çalışmalar seçildi. Veriler, dâhil edilme ve hariç tutulma kriterlerine göre iki araştırmacı tarafından toplandı. Apikal periodontitisli dişlerin oranı her kategori için kaydedildi: iyi yapılmış kök kanal dolgusu (IE), kötü yapılmış kök kanal dolgusu (KE), iyi yapılmış koronal restorasyon (iR), kötü yapılmış koronal restorasyon (KR). Veriler, olasılık oranları için meta-analiz kullanılarak analiz edildi. Önem seviyesi $\alpha=0.05$ olarak belirlendi.

BULGULAR: IE-KR ile IE-iR arasında [p=0.02 ve odds ratio $(\mathrm{OR})=1.88$, \%95 güven aralığı (GA; 1.13-3.13)], KE-iR ile IEiR arasında [ $p=0.006$ ve OR=3.23 (1.41-7.39)], KE-KR ile iEiR arasında [p<0.00001 ve OR=5.18 (2.62-10.23)], KE-iR ile IE- KR arasında [ $p=0.02$ ve OR=1.48 (1.07-2.03)], KE-KR ile IE-KR arasında $[p<0.0001$ ve $O R=2.44(1.69-3.51)]$ ve KEKR ile KE-IR arasında [p<0.00001 ve OR=1.80 (1.38-2.34)] istatistiksel olarak anlamlı bir fark vardı.

Sonuç: Mevcut en iyi kanıtlara dayanarak, apikal periodontitisin iyileşme olasılığı hem yeterli kök kanal tedavisi hem de yeterli restoratif tedavi ile artar. IE-KR'ye karşı KE-iR değerlendirildiğinde kök kanal dolgusunun koronal restorasyona göre daha önemli olduğu ortaya çıkmıştır.

ANAHTAR Kelimeler: Konik ışınlı bilgisayarlı tomografi; kök kanal tedavisin kalitesi, koronal restorasyonun kalitesi, periapikal durum, periapikal indeks

Makale gönderiliș tarihi: 9 Aralık 2020; Yayına kabul tarihi: 18 Mart 2021 * Iletișim: Dr. Fatih Çakıcı, Ordu Üniversitesi Diş Hekimliği Fakültesi,

Endodonti Anabilim Dalı, Ordu, Türkiye;

E-posta: dt fatihcakici@ hotmail.com

\begin{abstract}
Kaynak Göstermek İçin: Çakıcı EB, Çakıcı F. Periapikal sağlık üzerine koronal restorasyonun kalitesine karşı kök kanal tedavisinin kalitesinin etkisi: sistematik derleme ve meta-analiz. Acta Odontol Turc 2022;39(1):1-9
\end{abstract}

EdiтöR: Güven Kayaoğlu, Gazi Üniversitesi, Ankara, Türkiye

YAYıN HAKKı: @ 2022 Çakıcı ve Çakıcı. Bu eserin yayın hakkı Creative Commons Attribution License ile ruhsatlandırılmıştır. Sınırsız kullanım, dağıtım ve her türlü ortamda çoğaltım, yazarlar ve kaynağın belirtilmesi kaydıyla serbesttir.

Finansal Destek: Bulunmamaktadır.

ÇıKAR ÇATıŞMASI: Bulunmamaktadır.

[Abstract in English is at the end of the manuscript]

\section{Giriş}

Apikal periodontitis, kök kanal sistemi içerisindeki mikroorganizmalara karşı periapikal dokuların inflamatuar cevabıdır. Bu hastalık çoğu Avrupa ülkesi, Kuzey Amerika, Japonya ve birçok dünya ülkesinde medikal ve ekonomik yansımalara sebep olan yaygın bir sağlık problemidir. ${ }^{1}$ Apikal periodontitis, kanal tedavisi yapılan hastalarda \%35.9 iken kanal tedavisi yapılmayan hastalarda \%2.1 oranında görülür. ${ }^{2}$ Literatürde endodontik tedaviden sonra kök kanallarının bakterilerden korunması için apikal ve koronal olarak üçboyutlu, sızdırmaz bir şekilde doldurulması konusunda fikir birliği mevcuttur. ${ }^{3-7}$ Buna karşın, yaklaşık 25-30 yıldır kök kanal tedavisi yapılmış dişlerde periapikal sağlık üzerine kök kanal dolgusunun mu yoksa koronal restorasyonun kalitesinin mi daha çok etkili olduğuna dair hararetli tartışmalar devam etmektedir. ${ }^{7-11}$ Ray ve Trope $^{12} 1995$ yılında periapikal sağlık üzerine yaptıkları çalışmalarında, koronal restorasyonun kök kanal dolgusundan daha etkili olduğunu belirterek endodonti alanında önemli bir tartışmanın fitilini ateşlemişlerdir. $\mathrm{Bu}$ çalışmadan elde edilen sonuç, klinisyenleri, kök kanal tedavisinden hemen sonra yüksek kaliteli kalıcı bir restorasyonla tedaviyi bitirmek veya apikal periodontitisin çözülmesini beklemek için sızıntı yapma şansı daha yüksek olan geçici bir restorasyon yerleştirme konusunda kararlarını yeniden gözden geçirmeye itmiştir. 
$\mathrm{Bu}$ konuda gözlemsel, tanımlayıcı, kesitsel çalışmalar, retrospektif ve prospektif çalışmalar gibi çok çeşitli çalışmalar mevcuttur. ${ }^{7}$ Kesitsel çalışmalarda hastalık ve hastalar zamanın belirli bir anında değerlendirilir. Bu çalışmalar, hastalığın prevelansı, tanı ve mekanizmasını saptayan, neden sonuç ilişkisini aynı düzlemde inceleyen çalışmalardır. Kesitsel çalışmalar diğer çalışma tiplerine göre sonuçlandırma açısından hızlı olduklarından avantaj sağlarlar. ${ }^{13}$

Periapikal lezyonların varlığını değerlendirmek için kullanılan görüntüleme teknikleri; periapikal radyografiler, panoramik ve konik ışınlı bilgisayarı tomografilerdir. Konvansiyonel radyografilerin (periapikal ve panoramik) düşük maliyet, daha az radyasyon miktarı ve ulaşım kolaylığı gibi avantajları olmasına rağmen görüntü kalitesi ve tanı kesinliği tartışmalıdır.14-16 Konik ışınlı bilgisayarlı tomografi (KIBT) lezyon tiplerini belirlemek için kullanıldığında çok net bilgi verir ve bölgenin üç-boyutlu olarak değerlendirilmesine olanak sağlar. ${ }^{17-20}$ Periapikal lezyon ve kök rezorpsiyonlarının teşhisinde, kök kanal konfigürasyonlarının belirlenmesinde KIBT'nin konvansiyonel radyografilere üstünlük sağladığı çalışmalarla gösterilmiştir. ${ }^{15,16}$ Yapılan araştırmalarda konvansiyonel radyografiler ile koyulan tanının, KIBT kullanıldığında yaklaşık \%62'sinin değiştiği bildirilmiştir. ${ }^{21}$ Apikal periodontitis çalışmalarında, değerlendirme aracı olarak 90'lar ve 2000'li yıllarda popüler olması nedeniyle 2-boyutlu radyografiler kullanılmış, daha sonraki yıllarda KIB tomografinin diş hekimliği alanındaki kullanımının artması ile 2-boyutlu radyografilerin kullanıldığı çalışmaların yerini KIBT ile yürütülen çalışmalar almıştır.

$\mathrm{Bu}$ sistematik derleme ve meta-analizin amacı; önceki çalışmalardan elde edilen bulgulara dayanarak periapikal sağlık üzerine kök kanal dolgusunun kalitesinin mi yoksa koronal restorasyonun kalitesinin mi daha etkili olduğunu gösteren, KIBT ile yapılan bireysel çalışmaları kullanarak bir meta-analiz yapmak ve özetlemektir. Bu sistematik derleme ve meta-analizde yanıtlanacak klinik sorusu aşağıdaki gibi çerçevelenebilir: Cerrahi olmayan kanal tedavisi yapılmış (iyi veya kötü yapılmış kök kanal tedavisi ve koronal restorasyon) yetişkin hastalarda, kök kanal dolgusunun kalitesine karşı koronal restorasyonun kalitesinin periapikal sağlık üzerine etkilerini karşılaştırmak.

\section{Gereç Ve Yöntem}

Çalışmanın yürütülmesi ve sonuç raporunun yazıımasında, sistematik derleme veya meta-analiz araştırma raporunda bulunması gereken maddelerle ilgili kontrol listesi (PRISMA) protokolü takip edilmiştir. ${ }^{22}$

Çalışmamızda kullandığımız popülasyon, müdahale, karşılaştırma, sonuç, çalışma dizaynı soruları:

Popülasyon: Cerrahi olmayan kök kanal tedavisi yaptıran hastalar,
Müdahale: İyi veya kötü yapılmış kök kanal tedavisi ve üst restorasyon,

İyi endodontik tedavi: Tüm kanallar boşluksuz bir şekilde sıkıca doldurulmuş ve kök kanal dolgusu apikal 0-2 $\mathrm{mm}$ sınırları içerisinde,

Kötü endodontik tedavi: Yukarıdaki koşulları sağlamayan,

İyi koronal restorasyon: Restorasyonun tamamının görüldüğü restorasyonlar,

Kötü koronal restorasyon: Yukarıdaki koşulları sağlamayan,

Karşılaştırma: Aşağıda sıralandığı gibi 6 karşılaştırma yapılmıştır:

1. İyi yapılmış endodontik tedavi (IE) - iyi yapılmış koronal restorasyona (IR) karşı iyi yapılmış endodontik tedavi (IE) - kötü yapılmış koronal restorasyon (KR) [iEiR vs iE-KR]

2. İyi yapılmış endodontik tedavi (IE) - iyi yapılmış koronal restorasyona (IR) karşı kötü yapılmış endodontik tedavi (KE) - iyi yapılmış koronal restorasyon (IR) [iE-iR / KE-IR]

3. İyi yapılmış endodontik tedavi (IE) - iyi yapılmış koronal restorasyona (IR) karşı kötü yapılmış endodontik tedavi (KE) - kötü yapılmış koronal restorasyon (KR) [íE-IR / KE-KR]

4. İyi yapılmış endodontik tedavi (IE) - kötü yapılmış koronal restorasyona $(\mathrm{KR})$ karşı kötü yapılmış endodontik tedavi (KE) - iyi yapılmış koronal restorasyon (IR) [iEKR / KE-IR]

5. İyi yapılmış endodontik tedavi (IE) - kötü yapılmış koronal restorasyona (KR) karşı kötü yapılmış endodontik tedavi (KE) - kötü yapılmış koronal restorasyon (KR) [iE-KR / KE-KR]

6. Kötü yapılmış endodontik tedavi (KE) - iyi yapıımış koronal restorasyona (IRR) karşı kötü yapılmış endodontik tedavi (KE) - kötü yapılmış koronal restorasyon (KR) [KE-iR / KE-KR]

Sonuç: Periapikal sağlık düzeyi

Periapikal durum: Periodontal ligament boşluğunda $\geq 0.5 \mathrm{~mm}$ radyolusensi lezyon ya da sağlıksız olarak değerlendirildi.

Çalışma dizaynı: Kesitsel çalışmalar

\section{Araştırma stratejisi}

Pubmed veri tabanında 1 Ocak 2000 - 27 Haziran 2020 tarihleri arasında online veya tam basılan makaleler tarandı. "endodontics AND periapical index", "endodontics AND periapical status", "quality of root canal treatment AND periapical status", "quality of root canal treatment AND periapical index", "root canal treatment AND periapical index", "root canal treatment AND periapical status", "root treatment AND periapical index", "root treatment AND periapical status", "root canal treatment AND coronal restoration", "quality of root canal treatment AND cone beam computed tomography", "periapical index AND cone beam computed tomography", "periapical status AND cone beam computed 
tomography", "coronal restoration AND cone beam computed tomography", "coronal restoration AND periapical index", "coronal restoration AND periapical status", "restoration AND periapical index", "restoration AND periapical status" anahtar kelimeleri girilerek tarama yapıldı. İlaveten manuel tarama yapıldı; okunan yayınların referanslarına girilerek Pubmed veri tabanında olan yayınlar da çalışmaya dâhil edildi.

Tüm yayın tarama işlemleri birbirinden bağımsız şekilde iki yazar tarafından yürütüldü. Anlaşmazlık durumlarında aralarında konuşarak fikir birliğine vardılar. Tüm çalışmalardan yukarıda bahsi geçen gruplara uygun olarak veriler alındı.

\section{Dâhil edilme kriterleri:}

1. Periapikal durumu, endodontik tedavinin ve koronal restorasyonun kalitesi ile ilişkilendiren çalışmalar,

2. Başarı sayılarını veren veya ham verilerden başarı sayılarının hesaplanabileceği durumlar,

3. KIBT kullanan çalışmalar,

Hariç tutulma (dışlanma) kriterleri:

1. Sadece belirli hastalık veya durumların periapikal dokular üzerine etkilerini inceleyen çalışmalar,

2. Periapikal cerrahi yapılan hastalar,

3. In vitro çalışmalar, histolojik çalışmalar ve hayvan çalışmaları,

4. Sadece çocuk veya yaşlı hastaların dâhil edildiği çaIışmalar,

5. Radyografik değerlendirmeye ek olarak uzun süreli klinik değerlendirme yapılan çalışmalar,

6. Sadece öğrencilerin yaptıkları tedavi sonuçlarını değerlendiren çalışmalar,

7. Vaka raporları,

8. Sadece retreatment yapılmış hastaların sonuçlarını paylaşan çalışmalar,

9. Alışkanlıklar ve oral hijyene göre sınıflandırma yapılan çalışmalar,

10. Uzun süreli takip çalışmaları,

11. Bir alet veya yöntemin değerlendirildiği çalışmalar,

12. İngilizce ve Türkçe dışındaki diller,

13. İki-boyutlu radyografiler ile KIBT karşılaştıran çalışmalar,

14. Tedavi sonucunun periapikal durumun tek başına koronal restorasyondan mı yoksa endodontik tedavinin kalitesinden mi etkilendiğinin hesaplanamadığı çalışmalar,

15. Periapikal indeks oluşturmaya yönelik çalışmalar,

16. Sadece bir dental problem sonrası etkilenen periodontal durumu inceleyen çalışmalar,

17. Değerlendirme kriterine uymayan çalışmalar (yukarıda belirtiğimiz gibi iyi ve kötü yapılmış endodontik tedavi ve restorasyon tanımlarından farklı tanımlar veya
Sınıflandırmalar kullanarak sonuç elde etmiş çalışmalar),

18. Maksiller sinüzit ve mukoza ile periapikal lezyonu birlikte değerlendiren çalışmalar,

19. Anatomik çeşitlilikleri değerlendiren çalışmalar

\section{Kalite değerlendirmesi}

Kalite değerlendirmesi, son zamanlardaki gözlemsel çalışmalar ve randomize olmayan klinik çalışmalar için tavsiye edilen Robins I tool ve yayın yanlılığı için Cochrane Collobration (The Nordic Cochrane Center, The Cochrane Collaboration, Kopenhag, Danimarka) yaygın şemasına göre yürütüldü. ${ }^{23}$

1. Karışıklığa sebep olan yanlılık: Kafa karıştırıcı faktörler (hastalık vs).

2. Katılımcıların seçimi: Hastalar farklı yerlerden veya diş kliniklerinden ele alındığında ve / veya örneklem büyüklüğü hesaplaması yapılmadığında.

3. Müdahalelerin sınıflandırıması: iE/KE ve IR/KR tanımlarının iyi yapılması, sınıflandırmanın sınırlarının belirlenmesi.

4. Müdahalelerden sapma: Müdahaleler arasındaki farlılık (sonuçları etkilemeyecek şekilde olmalı).

5. Kayıp veriler: Periapikal lezyonun tek başına koronal restorasyonla mı yoksa kök kanal dolgusu veya ikisinin birleşik etkisiyle mi olduğunu belirleyebilmek.

6. Sonuçların ölçülmesi: Kök kanal tedavisinin kalitesini değerlendirmek için kullanılan kriterler, koronal restorasyonun kalitesini değerlendirmek için kullanılan kriterler.

7. Raporlanmış soruların seçilmesi: Gruplar arasındaki apikal periodontitis yaygınlığını raporlama.

Her bir çalışma yukarıdaki kriterlere göre düşük, ılımlı, ciddi, kritik ve bilgi yok şeklinde kaydedildi.

\section{İstatistiksel analiz}

Çalışma sonuç ölçüsü periapikal lezyonunun olasılık oranı (odds ratio; OR) olarak seçildi. Genel etki büyüklüğü olasılık oranından hesaplandı. Z-test istatistiği kullanıldı. Analizler sabit ve rastgele etki modelleri kullanılarak yapıldı. Çalışmalar arasındaki heterojenliği ölçmek için $\tau^{2}$, Ki-kare ve $\mathrm{I}^{2}$ istatistikleri kullanıldı. $\mathrm{I}^{2} \leq$ $\% 50$ ise, sabit etki modeli kullanılmıştır; aksi takdirde rastgele etki modeli kullanımıştır. ${ }^{24}$ Bizim meta-analizimizde yayın yanlılığı olup olmadığı Egger regresyon yöntemi ile test edildi. ${ }^{25}$ Tüm istatistiksel analizler, Cochrane Collaboration (The Nordic Cochrane Center, The Cochrane Collaboration, Kopenhag, Danimarka) tarafından sağlanan istatistiksel yazılım RevMan 5.4 kullanılarak gerçekleştirildi. Önem seviyesi $\alpha=0.05$ olarak belirlendi. 


\section{BULGULAR}

Yukarıda verilen anahtar kelimeler ve el ile yapılan tarama sonucunda 2,942 $(2,927$ + 15) çalışma elde edildi. Bu çalışmalardan duplikasyonlar (farklı aramalarda çıkan aynı çalışmalar) çıkarıldı ve toplam 1,090 çalışma kaldı. Bu çalışmaların başlıkları ve özetleri okunarak çalışmamızla ilgisi olmadığı kanısına vardığımız 1,051 çalışma dışarda bırakıldı. Bu çalışmaların sadece 39 tanesi bizim çalışmamızla ilgiliydi. Bu çalışmaların tam metnine ulaşıldı. Aşağıdaki sebeplerden dolayı 36 tanesi daha çıkarıldı ve geriye kalan 3 adet çalışma meta-analizimize dâhil edildi (Şekil 1). Bu 36 çalışmanın dışarıda bırakılma sebepleri Tablo 1'de belirtilmiştir.

\section{Karşılaştırma: iE-KR / iE-iR}

Üç çalışmadan ${ }^{5,62,63}$ elde edilen veriler bir araya getirildiğinde makul bir heterojenlik $\left(\mathrm{I}^{2}=\% 54, \mathrm{Tau}^{2}=0.11\right.$ ve $\left.\mathrm{chi}^{2}=4.39\right)$ vardı; bu nedenle, bir rastgele etki analizi modeli kullanıldı. Bu meta-analiz, IE-iR grubundaki hastaların IE-KR grubundaki hastalara kıyasla periapikal sağlık yönünden daha sağlıklı olduğunu ortaya çıkardı; yani $p=0.02$ ve $O R=1.88, \% 95$ güven aralığı (GA: 1.13-3.13); Şekil 2.

\section{Karşılaştırma: KE-iR / IE-iR}

Üç çalışmadan ${ }^{5,62,63}$ elde edilen veriler bir araya getirildiğinde hatırı sayılır bir heterojenlik $\left(\mathrm{I}^{2}=\% 96\right.$, $\mathrm{Tau}^{2}=$ 0.51 ve $\left.\mathrm{chi}^{2}=47.52\right)$ vardı; bu nedenle, bir rastgele etki analizi modeli kullanıldı. Bu meta-analiz, IE-IR grubundaki hastaların KE-iR grubundaki hastalara kıyasla periapikal sağlık yönünden daha sağlıklı olduğunu ortaya çıkardı; yani p=0.006 ve OR=3.23 (1.41-7.39); Şekil 2.

\section{Karşılaştırma: KE-KR / IE-iR}

Üç çalışmadan ${ }^{5,62,63}$ elde edilen veriler bir araya getirildiğinde önemli bir heterojenlik $\left(\mathrm{I}^{2}=\% 72, \mathrm{Tau}^{2}=0.26\right.$ ve $\mathrm{chi}^{2}=7.13$ ) vardı; bu nedenle, bir rastgele etki analizi modeli kullanıldı. Bu meta-analiz, IE-IR grubundaki hastaların KE-KR grubundaki hastalara kıyasla periapikal sağlık yönünden daha sağlıklı olduğunu ortaya çıkardı; yani $p<0.00001$ ve OR=5.18 (2.62-10.23); Şekil 2.

\section{Karşılaştırma: KE-iR / IE- KR}

Üç çalışmadan ${ }^{5,62,63}$ elde edilen veriler bir araya getirildiğinde makul bir heterojenlik $\left(\mathrm{I}^{2}=\% 43\right.$, chi $\left.^{2}=3.53\right)$ vardı; bu nedenle, bir sabit etki analizi modeli kullanıldı (sabit etki modeli kullanıldığı için $\mathrm{Tau}^{2}$ verilmemiştir). Bu meta-analiz, IE-KR grubundaki hastaların KE-iR grubundaki hastalara kıyasla periapikal sağlık yönünden daha sağlıklı olduğunu ortaya çıkardı; yani $p=0.02$ ve OR=1.48 (1.07-2.03); Şekil 3.

\section{Karşılaştırma: KE-KR/ iE-KR}

Üç çalışmadan ${ }^{5,62,63}$ elde edilen veriler bir araya getirildiğinde önemli bir heterojenlik $\left(\mathrm{I}^{2}=\% 0\right.$, chi $\left.^{2}=1.03\right)$ yoktu; bu nedenle, bir sabit etki analizi modeli kullanıldı (sabit etki modeli kullanıldığı için $\mathrm{Tau}^{2}$ verilmemiştir). Bu meta-analiz, IE-KR grubundaki hastaların KE-KR grubundaki hastalara kıyasla periapikal sağlık yönünden daha sağlıklı olduğunu ortaya çıkardı; yani $p<0.0001$ ve OR=2.44 (1.69-3.51); Şekil 3.

\section{Karşılaştırma: KE-KR/ KE-IR}

Üç çalışmadan ${ }^{5,62,63}$ elde edilen veriler bir araya getirildiğinde önemli bir heterojenlik $\left(\mathrm{I}^{2}=\% 0\right.$, chi $\left.^{2}=0.87\right)$ yoktu; bu nedenle, bir sabit etki analizi modeli kullanıldı (sabit etki modeli kullanıldığı için $\mathrm{Tau}^{2}$ verilmemiştir). Bu meta-analiz, KE-KR grubundaki hastaların KE-IR grubundaki hastalara kıyasla periapikal sağlık yönünden daha sağlıklı olduğunu ortaya çıkardı; yani $p<0.00001$ ve $\mathrm{OR}=1.80$ (1.38-2.34); Şekil 3.

Tablo 1. Meta-analizden çıkarılan çalışmaların sebepleri

\begin{tabular}{|c|c|}
\hline Dışlanma sebebi & Dışlanan çalışmalar \\
\hline Bir alet veya yöntemin değerlendirildiği çalışmalar & de-Figueiredo ${ }^{26}$, Huumonen ve ark. ${ }^{27}$, de Figueiredo ve ark. ${ }^{28}$ \\
\hline $\begin{array}{l}\text { Sadece belli hastalık veya durumların periapikal dokular üzerine etkilerini } \\
\text { inceleyen çalışmalar }\end{array}$ & Sisli SN ${ }^{29}$ \\
\hline Periapikal index oluşturmaya yönelik çalışmalar & Torabinejad ve ark. ${ }^{30}$, Esposito ve ark. ${ }^{31}$ \\
\hline $\begin{array}{l}\text { Tedavi sonucunun tek başına koronal restorasyonla mı yoksa endodontik } \\
\text { tedavinin kalitesinden mi etkilendiğini gösteremeyen çalışmalar }\end{array}$ & Lemagner ve ark. ${ }^{32}$, Burklein ve ark. ${ }^{33}$ \\
\hline 2-boyutlu radyografiler ile KIBT’yi karşılaştıran çalışmalar & $\begin{array}{l}\text { Liang ve ark. }{ }^{34} \text {, Patel ve ark. }{ }^{35} \text {, Patel ve ark. }{ }^{18} \text {, Venskutonis ve ark. }{ }^{36} \text {, } \\
\text { Pope ve ark. }{ }^{37} \text {, Cheung ve ark. }{ }^{38}\end{array}$ \\
\hline İngilizce ve Türkçe dışındaki diller & Ma ve ark. ${ }^{39}$, Chen ve ark. ${ }^{40}$ \\
\hline $\begin{array}{l}\text { Maksiller sinüzit ve mukoza ile periapikal lezyonu birlikte değerlendiren } \\
\text { çalışmalar. }\end{array}$ & $\begin{array}{l}\text { Khorramdel ve ark. }{ }^{41} \text {, Souza-Nunes ve ark. }{ }^{42} \text {, Sakir ve ark. }{ }^{43} \text {, } \\
\text { Nurbakhsh ve ark. }{ }^{44} \text {, Nunes ve ark. }{ }^{45}\end{array}$ \\
\hline Tek diş veya kök kanalı değerlendiren çalışmalar & Shetty ve ark. ${ }^{46}$ \\
\hline Değerlendirme kriteri & Nur ve ark. ${ }^{47}$, Cakici ve ark. ${ }^{48}$ \\
\hline Vaka raporları & de Paula ve ark. ${ }^{49}$, Kato ve ark. ${ }^{50}$ \\
\hline Anatomik çeşitlikleri değerlendiren çalışmalar & Mashyakhy ve ark. ${ }^{51}$, Saati ve ark. ${ }^{52}$, Mashyakhy ve ark. ${ }^{53}$ \\
\hline Periapikal cerrahi yapılan hastalar & von Arx ve ark. ${ }^{54}$ \\
\hline Alışkanlıklar ve oral hijyene göre sınıflandırma yapılan çalışmalar & Balto ve ark. ${ }^{55}$ \\
\hline $\begin{array}{l}\text { Sadece bir dental problem sonrası etkilenen periodontal durumu } \\
\text { inceleyen çalışmalar }\end{array}$ & Abella ve ark. ${ }^{56}$ \\
\hline In vitro çalışmalar, histolojik çalışmalar ve hayvan çalışmaları & Kruse ve ark. ${ }^{57}$ \\
\hline $\begin{array}{l}\text { 2-boyutlu radyografiler ile KIBT karşılaştıran çalışmalar. Uzun süreli takip } \\
\text { çalışmaları }\end{array}$ & $\begin{array}{l}\text { Restrepo-Restrepo ve ark. }{ }^{58} \text {, Mashyakhy ve ark. }{ }^{59} \text {, de Freitas ve ark. }{ }^{60} \text {, } \\
\text { Liang ve ark. }{ }^{61}\end{array}$ \\
\hline
\end{tabular}




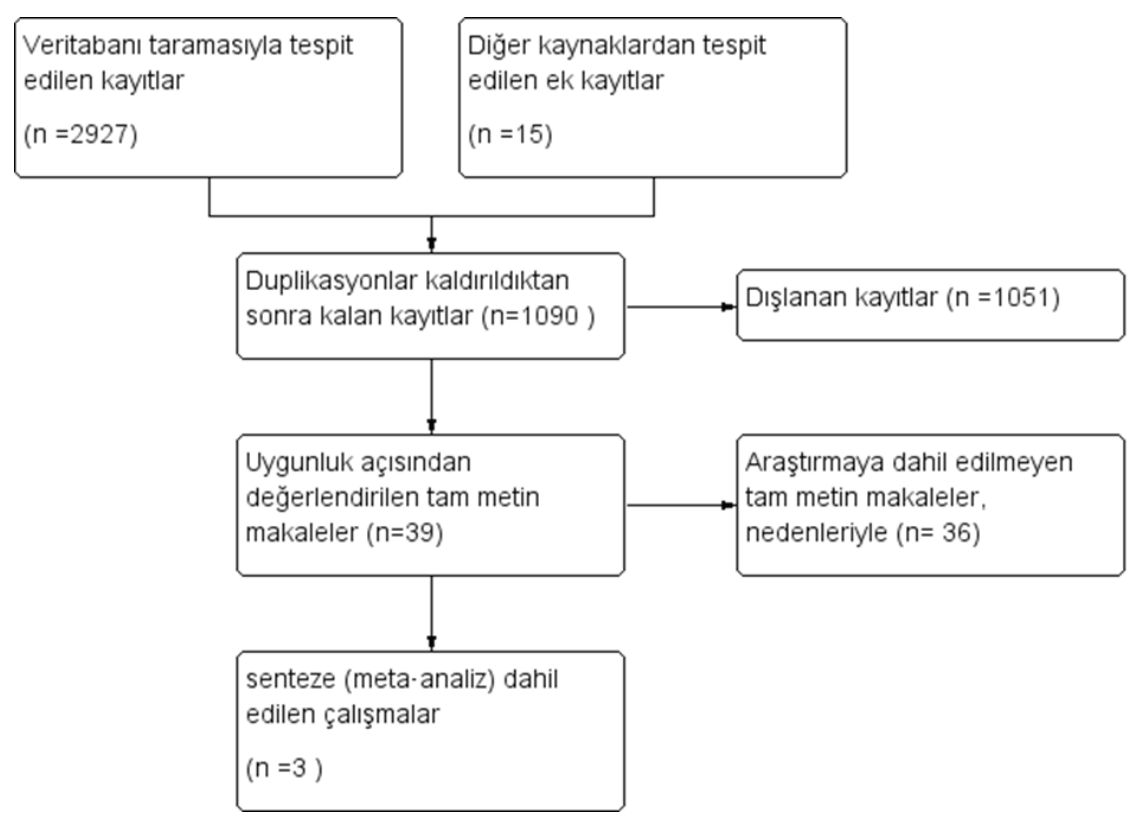

Şekil 1. Literatür arama ve seçim kriterlerinin akış diyagramı (PRISMA 2009 akış şemasından uyarlanmıştır)

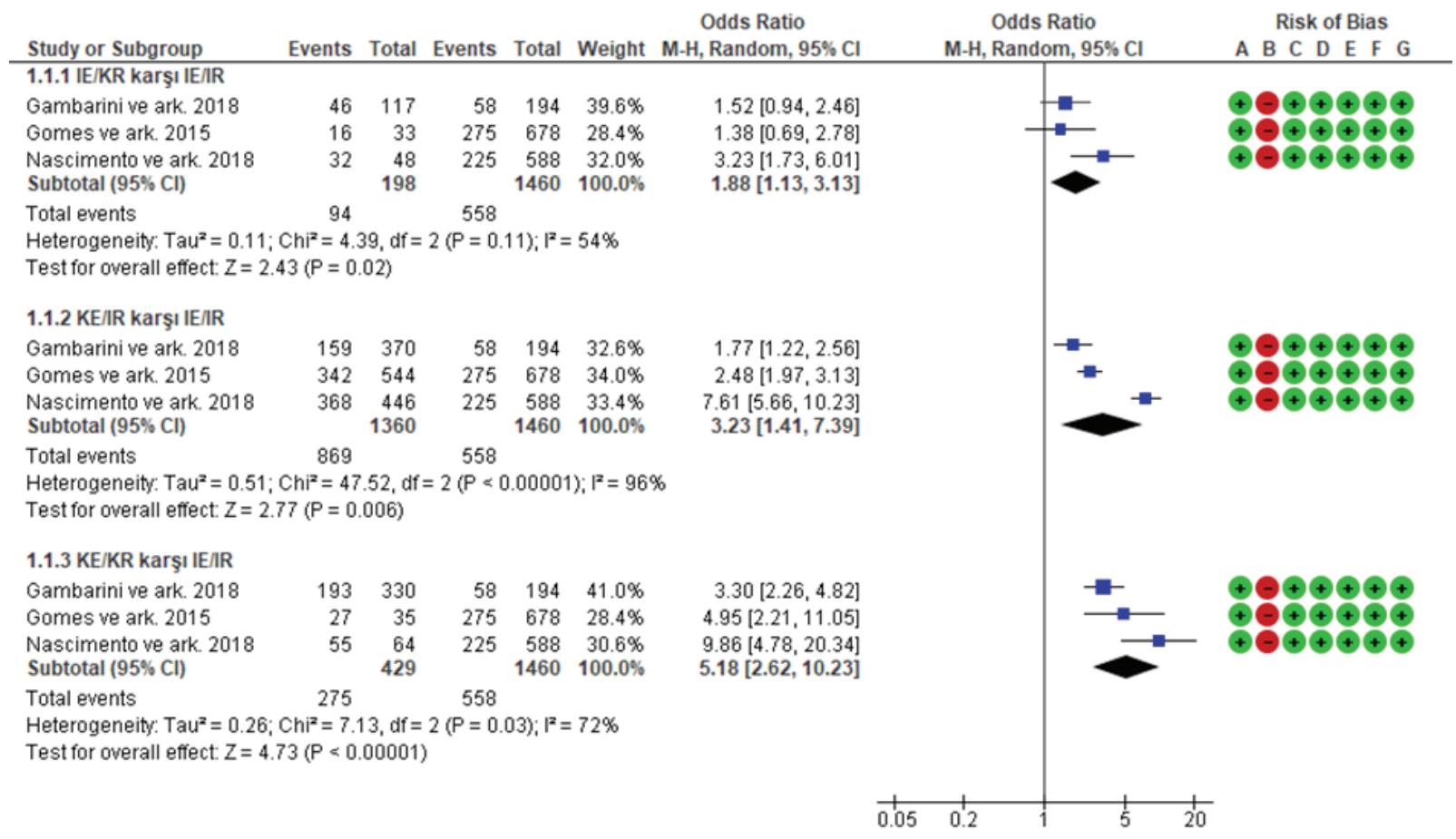

Risk of bias legend
(A) Karıșıklığa sebep olan yanlılık
(B) Katılımcıların seçimi
(C) Müdahalelerin sınıflandırılması
(D) Müdahalelerden sapma
(E) Kayıp veriler
(F) Sonuçların ölçülmesi
(G) Raporlanmış soruların seçilmesi

Şekil 2. IE-KR karşı IE-IR, KE-iR karşı IE-iR ve KE-KR karşı IE/IR karşılaştıran çalışmaların orman grafiği ve yayın yanlılığını gösteren şekil 


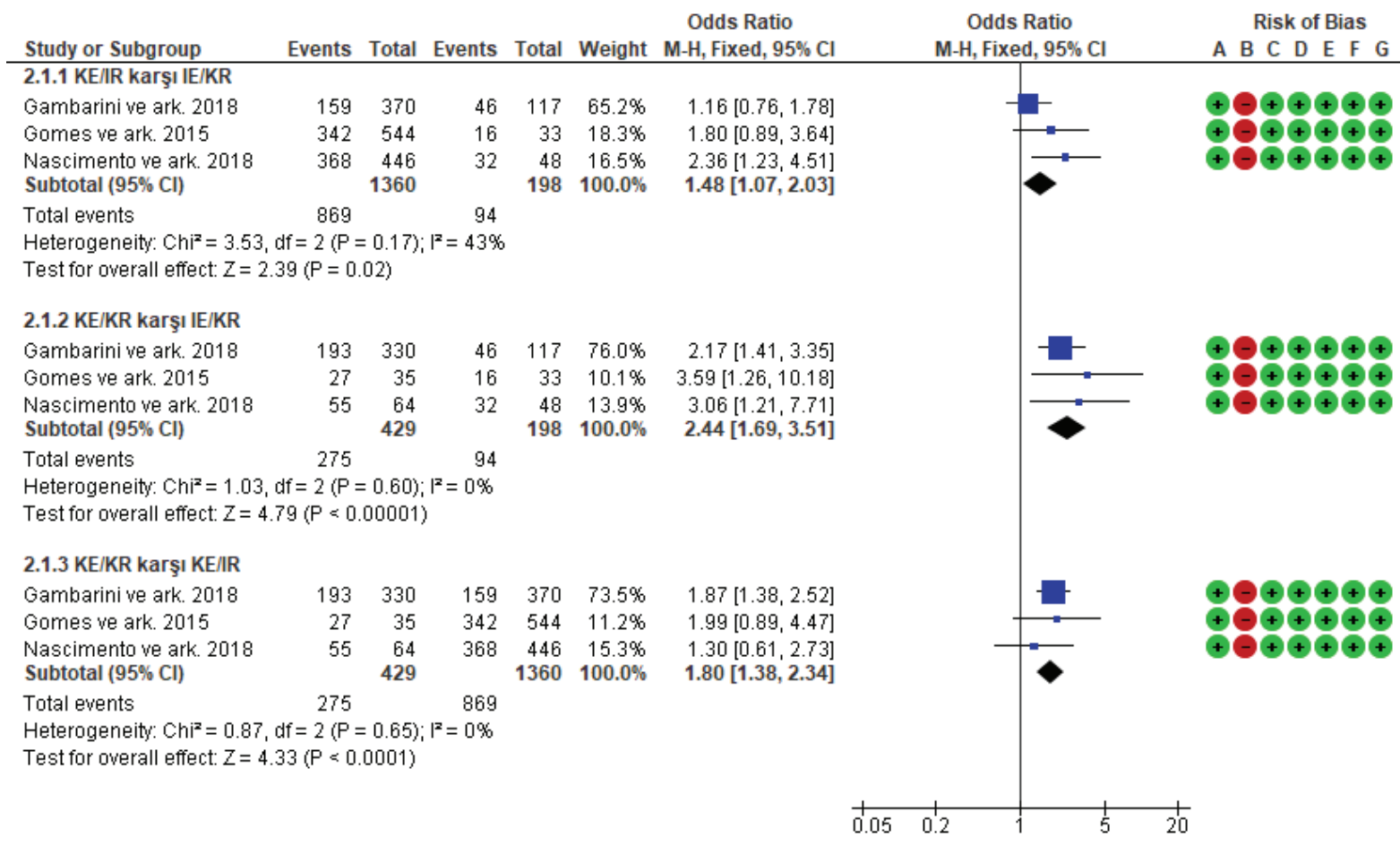

Risk of bias leqend

(A) Karıșıklığa sebep olan yanlılık

(B) Katılımcıların seçimi

(C) Müdahalelerin sınıflandırılması

(D) Müdahalelerden sapma

(E) Kayıp veriler

(F) Sonuçların ölçülmesi

(G) Raporlanmıș soruların seçilmesi

Şekil 3. KE-iR karşı IE-KR, KE-KR karşı IE-KR ve KE-KR karşı KE-IR karşılaştıran çalışmaların orman grafiği ve yayın yanlıı̆ını gösteren şekil

\section{Kalitenin değerlendirmesi}

Dâhil edilen çalışmaların hepsinde yalnızca bir konuda yüksek yayın yanlılığı (katılımcıların seçimi) olduğu için bütün çalışmalar düşük risk gruplu çalışmalar olarak kategorize edildi.

Bizim meta-analizimizde yayın yanlılığı olup olmadığı Egger Regresyon Yöntemi ile test edildi. ${ }^{25} \mathrm{Bu}$ analize göre 1. karşılaştırmada $p=0.83,2$. karşılaştırmada $p=0.99$, 3. karşılaştırmada $p=0.39$, 4. karşılaştırmada $p=0.28,5$. karşılaştırmada $p=0.06$ ve 6 . karşılaştırmada $p=0.66$ bulundu. Dolayısıyla bu karşılaştırmalarda yayın yanlılığı tespit edilmedi.

\section{TARTIŞMA}

Mevcut sistematik derlemelerdeki çalışmaların çoğu gözlemsel kohort çalışmalarından elde edilen çalışmalardır. Gözlemsel çalışmaların meta-analizi kontrol deneme meta-analizleri kadar yaygındır. ${ }^{64}$ Stroup ve ark. ${ }^{65} 2000$ yılında yaptıkları çalışmada gözlemsel meta-analizin nasıl yapılacağını tanımlamışlardır. Gözlemsel çalışmalardan elde edilen veriler, verilerin yayın yanlılığına dikkat edilerek analiz edilmesi ve yorumlanması durumunda, rastgele kontrollü çalışmalar yapılamadığı veya yapılmaması gerektiği durumlarda önemli bir bilgi kaynağı sağlar. Kanıta dayalı endodonti, sistematik olmayan klinik deneyimin ve vaka raporlarının aksine, yüksek düzeyde klinik çalışmalardan elde edilen kanıtların incelenmesini vurgular. Randomize denemelerin önemi, klinik kanıt hiyerarşisi kavramına dayanmasına rağmen, bugüne kadar endodontide üretilen sonuç araştırmalarının çoğu, doğası gereği gözlemsel kalmaktadır. ${ }^{7}$

Kesitsel çalışmalar pre-post operatif diagnoz içermeyen çalışmalardır. Bu çalışmalarda görülen apikal periodontitis, kök kanal tedavisinden önce var olan ve iyileşmekte olan bir apikal periodontitis olabileceği gibi aynı zamanda kök kanal tedavisinden önce olmayan ve endodontik tedaviden sonra oluşmaya başlayan bir lezyon da olabilir. Bu sonuçlar da kesitsel çalışmaların sınırlarını teşkil eder. Bu çalışma tiplerinde, verileri değerlendiren araştırmacılar objektif sonuçların getireceği hataları önlemek için iki veya daha fazla araştırmacının aynı verileri inceleyerek fikir birliğine vardıkları sonuçları yayınlarlar. Böylece, elde edilen verilerin güvenilirliği artırılmış olur. Bizim analizimizde kullandığımız çalışmaların tamamında iki gözlemci kullanıımış ve aralarındaki anlaşma oranları ortaya konulmuştur.

Endodontik tedavinin sonuçları, farklı yöntemler kullanılarak yapılan çok sayıda çalışmanın konusu olmuş- 
tur. İnsan üzerinde yapılan çalışmalarda tüm faktörlerin sabitlenememesinin yanı sıra çalışmaların metotlarındaki farklılık ve bir standardizasyon sağlanamaması çalışmaların karşılaştırılmasını zorlaştırmıştır. Apikal periodontitis, periapikal dokuların kök kanal sistemindeki mikroorganizmalar ile kontamine olması sonucu gelişir. ${ }^{66}$ Çok sayıda in vitro çalışmada, en iyi teknikler ile yapılan kök kanal tedavilerinde bile mikroorganizmalar ve onların ürünlerinin sızabileceği bildirilmiştir. ${ }^{67,68} \mathrm{Bu}$ durum, bariz kontaminasyon varlığında bile tüm hastalarda kesinlikle periapikal hastalığın gelişeceği anlamına gelmez.

1996 yılında yapılan bir çalışma, endodontik tedavinin hangi kısmının kanal tedavisinin sonucu üzerine daha büyük etkiye sahip olduğunu belirleme arayışlarında endodontik tedavi felsefesinde bir paradigma değişimine sebep olmuştur. ${ }^{12}$ Yapılan bu çalışma, koronal restorasyonun kalitesinin kök kanal tedavisinin kalitesinden daha fazla etkiye sahip olduğunu ileri sürmüştür. Bu çalışmadan sonra, çalışmanın sonucunu destekleyen ve karşı çıkan birçok çalışma endodonti literatüründe yer alamaya başlamıştır. , 62,63

Belirlenen üç çalışmanın sonucu ile yaptığımız meta-analiz çalışmasında kök kanal tedavisi ile koronal restorasyonun etkinliklerini karşılaştırdığımız zaman (KE-IR / IE-KR) periapikal sağlık üzerine endodontik tedavinin koronal restorasyondan daha etkili olduğu sonucu çıkmıştır (OR=1.48). Gillen ve ark. ${ }^{7}$ iki-boyutlu radyografiler ile endodontik tedavinin periapikal sağlık üzerine etkilerini inceledikleri çalışmada (KE-IR / IE-KR) gruplar arasında anlamlı bir fark olmadığını belirtmiştir. Bu iki meta-analiz arasındaki farklılık nedeni Gillen ve ark. $^{7}$ dâhil edilme kriterleri ve değerlendirme metotlarından kaynaklanabilir. Bizim çalışmamızda, periapikal bölgedeki 0.5 mm'den küçük değişikler sağlıklı olarak kabul edildi. Ancak Gillen ve ark. çalışmalarında Orstavik ve arkadaşlarının ${ }^{69}$ sınıflandırmasını kullandıkları için bu değişikliği periapikal lezyon olarak değerlendirmişlerdir. Bizim çalışmamızın sonucunda; kötü yapılmış endodontik tedavi ve üst restorasyonda (KE-KR) iyi yapılmış bir endodontik tedavi ve üst restorasyona göre (IE-IR) 5.18 kat daha fazla lezyon görülme intimali olduğu ortaya çıkmıştır. Bu sonuçları karşılaştırabileceğimiz bir çalışma olmadığından karşılaştırma yapamıyoruz.

Meta-analiz çalışmalarında analiz yapabilmek için en az iki çalışmaya intiyaç duyulmasına rağmen analize dahil edilen çalışma sayısı arttıkça analizin güvenilirliği artmaktadır. Az sayıda çalışma ile yapılan meta-analizlerde yayın yanlılığı riski olabilir. ${ }^{70}$ Bizim çalışmamızın limitleri dahilinde üç adet çalışma analiz edilmiş olmasına rağmen Egger Regresyon yöntemine ${ }^{25}$ göre yayın yanlılığı yoktur. Bunun sebebi analize dahil edilen çalışmaların sonuçlarının dağılımı olabilir. Tüm bunlara rağmen bu konu ile alakalı ileride yapılacak çalışmalarla daha güçlü analizler yapılabilir.

\section{Sonuç}

Mevcut en iyi kanıtlara dayanarak, apikal periodontitisin iyileşme olasılığı hem yeterli kök kanal tedavisi hem de yeterli restoratif tedavi ile artar. İyi yapılmış kök kanal dolgusu- yetersiz koronal restorasyon ile kötü yapılmış kök kanal dolgusu - iyi yapılmış koronal restorasyon karşılaştırıldıkları zaman kök kanal dolgusunun daha önemli olduğu ortaya çıkmıştır.

\section{TEŞEKKÜR VE ANMA}

Prof. Dr. Zekiye Karaçam'a katkılarında dolayı teşekkür ederiz.

\section{KAYNAKLAR}

1. Figdor D. Apical periodontitis: a very prevalent problem. Oral Surg Oral Med Oral Pathol Oral Radiol Endod 2002;94:651-2.

2. Pak JG, Fayazi S, White SN. Prevalence of periapical radiolucency and root canal treatment: a systematic review of cross-sectional studies. J Endod 2012;38:1170-6.

3. Sjogren U, Hagglund B, Sundqvist G, Wing K. Factors affecting the long-term results of endodontic treatment. J Endod 1990;16:498-504.

4. Ng YL, Mann V, Rahbaran S, Lewsey J, Gulabivala K. Outcome of primary root canal treatment: systematic review of the literature - part 1. Effects of study characteristics on probability of success. Int Endod J 2007;40:921-39.

5. Gomes AC, Nejaim Y, Silva AI, Haiter-Neto F, Cohenca N, Zaia AA, et al. Influence of Endodontic Treatment and Coronal Restoration on Status of Periapical Tissues: A Cone-beam Computed Tomographic Study. J Endod 2015;41:1614-8.

6. Song M, Park M, Lee CY, Kim E. Periapical status related to the quality of coronal restorations and root fillings in a Korean population. $\mathrm{J}$ Endod 2014;40:182-6.

7. Gillen BM, Looney SW, Gu LS, Loushine BA, Weller RN, Loushine $\mathrm{RJ}$, et al. Impact of the quality of coronal restoration versus the quality of root canal fillings on success of root canal treatment: a systematic review and meta-analysis. J Endod 2011;37:895-902.

8. Kabak Y, Abbott PV. Prevalence of apical periodontitis and the quality of endodontic treatment in an adult Belarusian population. Int Endod J 2005;38:238-45.

9. Frisk F, Hugoson A, Hakeberg M. Technical quality of root fillings and periapical status in root filled teeth in Jonkoping, Sweden. Int Endod J 2008;41:958-68.

10. Eckerbom M, Flygare L, Magnusson T. A 20-year follow-up study of endodontic variables and apical status in a Swedish population. Int Endod J 2007;40:940-8.

11. Chen CY, Hasselgren G, Serman N, Elkind MS, Desvarieux M, Engebretson SP. Prevalence and quality of endodontic treatment in the Northern Manhattan elderly. J Endod 2007;33:230-4.

12. Ray HA, Trope M. Periapical status of endodontically treated teeth in relation to the technical quality of the root filling and the coronal restoration. Int Endod J 1995;28:12-8.

13. Ceyda ÖÇ, Aslı D. Bilimsel Araştırma Nedir, Nasıl Yapılır? Turk J Anaesthesiol Reanim 2016;44:212-8.

14. Moura MS, Guedes OA, De Alencar AH, Azevedo BC, Estrela $C$. Influence of length of root canal obturation on apical periodontitis detected by periapical radiography and cone beam computed tomography. J Endod 2009;35:805-9.

15. Durack C, Patel S. Cone beam computed tomography in endodontics. Braz Dent J 2012;23:179-91.

16. Patel S, Durack C, Abella F, Shemesh H, Roig M, Lemberg K. Cone beam computed tomography in Endodontics - a review. Int Endod J 2015;48:3-15.

17. Estrela C, Bueno MR, Leles CR, Azevedo B, Azevedo JR. Accuracy of cone beam computed tomography and panoramic and periapical radiography for detection of apical periodontitis. J Endod 2008;34:273-9. 
18. Patel S, Wilson R, Dawood A, Foschi F, Mannocci F. The detection of periapical pathosis using digital periapical radiography and cone beam computed tomography - part 2: a 1-year post-treatment followup. Int Endod J 2012;45:711-23.

19. Weissman J, Johnson JD, Anderson M, Hollender L, Huson $\mathrm{T}$, Paranjpe $\mathrm{A}$, et al. Association between the Presence of Apical Periodontitis and Clinical Symptoms in Endodontic Patients Using Cone-beam Computed Tomography and Periapical Radiographs. J Endod 2015;41:1824-9.

20. Karabucak B, Bunes A, Chehoud C, Kohli MR, Setzer F. Prevalence of Apical Periodontitis in Endodontically Treated Premolars and Molars with Untreated Canal: A Cone-beam Computed Tomography Study. J Endod 2016;42:538-41

21. Ee J, Fayad MI, Johnson BR. Comparison of endodontic diagnosis and treatment planning decisions using cone-beam volumetric tomography versus periapical radiography. J Endod 2014;40:910-6.

22. Moher D, Liberati A, Tetzlaff J, Altman D. Preferred reporting items for systematic reviews and meta-analyses: the PRISMA statement. Int J Surg 2010;8:336-41.

23. Sterne JA, Hernan MA, Reeves BC, Savovic J, Berkman ND, Viswanathan M, et al. ROBINS-I: a tool for assessing risk of bias in non-randomised studies of interventions. BMJ 2016;355:i4919.

24. Higgins JP, Thompson SG, Deeks JJ, Altman DG. Measuring inconsistency in meta-analyses. BMJ 2003;327:557-60.

25. Egger M, Davey Smith G, Schneider M, Minder C. Bias in metaanalysis detected by a simple, graphical test. BMJ 1997;315:629-34

26. de-Figueiredo FED, Lima LF, Lima GS, Oliveira LS, Ribeiro MA, Brito-Junior $M$, et al. Apical periodontitis healing and postoperative pain following endodontic treatment with a reciprocating single-file, singlecone approach: A randomized controlled pragmatic clinical trial. PLoS One 2020;15:e0227347.

27. Huumonen S, Lenander-Lumikari M, Sigurdsson A, Orstavik D. Healing of apical periodontitis after endodontic treatment: a comparison between a silicone-based and a zinc oxide-eugenol-based sealer. Int Endod J 2003;36:296-301.

28. de Figueiredo FED, Lima LF, Oliveira LS, Ribeiro MA, Correa $M B$, Brito-Junior $M$, et al. Effectiveness of a reciprocating single file, single cone endodontic treatment approach: a randomized controlled pragmatic clinical trial. Clin Oral Investig 2020;24:2247-57.

29. Sisli SN. Evaluation of the Relationship between Type II Diabetes Mellitus and the Prevalence of Apical Periodontitis in Root-Filled Teeth Using Cone Beam Computed Tomography: An Observational CrossSectional Study. Med Princ Pract 2019;28:533-8.

30. Torabinejad M, Rice DD, Maktabi O, Oyoyo U, Abramovitch K. Prevalence and Size of Periapical Radiolucencies Using Conebeam Computed Tomography in Teeth without Apparent Intraoral Radiographic Lesions: A New Periapical Index with a Clinical Recommendation. J Endod 2018;44:389-94.

31. Esposito S, Cardaropoli M, Cotti E. A suggested technique for the application of the cone beam computed tomography periapical index. Dentomaxillofac Radiol 2011;40:506-12.

32. Lemagner F, Maret D, Peters OA, Arias A, Coudrais E, GeorgelinGurgel M. Prevalence of Apical Bone Defects and Evaluation of Associated Factors Detected with Cone-beam Computed Tomographic Images. J Endod 2015;41:1043-7.

33. Burklein S, Schafer E, Johren HP, Donnermeyer D. Quality of root canal fillings and prevalence of apical radiolucencies in a German population: a CBCT analysis. Clin Oral Investig 2020;24:1217-27.

34. Liang YH, Li G, Wesselink PR, Wu MK. Endodontic outcome predictors identified with periapical radiographs and cone-beam computed tomography scans. J Endod 2011;37:326-31.

35. Patel S, Wilson R, Dawood A, Mannocci F. The detection of periapical pathosis using periapical radiography and cone beam computed tomography - part 1: pre-operative status. Int Endod J 2012;45:702-10.

36. Venskutonis T, Plotino G, Tocci L, Gambarini G, Maminskas J, Juodzbalys G. Periapical and endodontic status scale based on periapical bone lesions and endodontic treatment quality evaluation using cone-beam computed tomography. J Endod 2015;41:190-6.

37. Pope O, Sathorn C, Parashos P. A comparative investigation of cone-beam computed tomography and periapical radiography in the diagnosis of a healthy periapex. J Endod 2014;40:360-5.

38. Cheung GS, Wei WL, McGrath C. Agreement between periapical radiographs and cone-beam computed tomography for assessment of periapical status of root filled molar teeth. Int Endod J 2013;46:889-95.

39. Ma L, Zhan FL, Qiu LH, Xue M. [The application of cone-beam computed tomography in diagnosing the lesions of apical periodontitis of posterior teeth]. Shanghai Kou Qiang Yi Xue 2012;21:442-6.

40. Chen $Q$, Zhang $X$. [The value of cone beam computed tomography in detecting suspicious vertical root fractures of molars on periapical radiographs]. Zhonghua Kou Qiang Yi Xue Za Zhi 2014;49:513-6.

41. Khorramdel A, Shirmohammadi A, Sadighi A, Faramarzi M, Babaloo AR, Sadighi Shamami M, et al. Association between demographic and radiographic characteristics of the schneiderian membrane and periapical and periodontal diseases using cone-beam computed tomography scanning: A retrospective study. J Dent Res Dent Clin Dent Prospects 2017;11:170-6.

42. Souza-Nunes LA, Verner FS, Rosado LPL, Aquino SN, Carvalho ACP, Junqueira RB. Periapical and Endodontic Status Scale for Endodontically Treated Teeth and Their Association with Maxillary Sinus Abnormalities: A Cone-beam Computed Tomographic Study. J Endod 2019;45:1479-88.

43. Sakir M, Ercalik Yalcinkaya S. Associations between Periapical Health of Maxillary Molars and Mucosal Thickening of Maxillary Sinuses in Cone-beam Computed Tomographic Images: A Retrospective Study. J Endod 2020;46:397-403.

44. Nurbakhsh B, Friedman S, Kulkarni GV, Basrani B, Lam E. Resolution of maxillary sinus mucositis after endodontic treatment of maxillary teeth with apical periodontitis: a cone-beam computed tomography pilot study. J Endod 2011;37:1504-11.

45. Nunes CA, Guedes OA, Alencar AH, Peters OA, Estrela CR, Estrela C. Evaluation of Periapical Lesions and Their Association with Maxillary Sinus Abnormalities on Cone-beam Computed Tomographic Images. J Endod 2016;42:42-6.

46. Shetty H, Sontakke S, Karjodkar F, Gupta P, Mandwe A, Banga KS. A Cone Beam Computed Tomography (CBCT) evaluation of MB2 canals in endodontically treated permanent maxillary molars. A retrospective study in Indian population. J Clin Exp Dent 2017;9:e51-e5.

47. Nur BG, Ok E, Altunsoy M, Aglarci OS, Colak M, Gungor E. Evaluation of technical quality and periapical health of root-filled teeth by using cone-beam CT. J Appl Oral Sci 2014;22:502-8.

48. Cakici EB, Yildirim E, Cakici F, Erdogan AS. Assessment of periapical health, quality of root canal filling, and coronal restoration by using cone-beam computed tomography. Niger J Clin Pract 2016;19:673-7.

49. de Paula AF, Brito-Junior M, Quintino AC, Camilo CC, Cruz-Filho AM, Sousa-Neto MD. Three independent mesial canals in a mandibular molar: four-year followup of a case using cone beam computed tomography. Case Rep Dent 2013;2013:891849.

50. Kato $\mathrm{H}$. Non-surgical endodontic treatment for dens invaginatus type III using cone beam computed tomography and dental operating microscope: a case report. Bull Tokyo Dent Coll 2013;54:103-8.

51. Mashyakhy M, Chourasia HR, Halboub E, Almashraqi AA, Khubrani Y, Gambarini G. Anatomical variations and bilateral symmetry of roots and root canal system of mandibular first permanent molars in Saudi Arabian population utilizing cone- beam computed tomography. Saudi Dent J 2019;31:481-6.

52. Saati S, Shokri A, Foroozandeh M, Poorolajal J, Mosleh N. Root Morphology and Number of Canals in Mandibular Central and Lateral Incisors Using Cone Beam Computed Tomography. Braz Dent J 2018;29:239-44.

53. Mashyakhy $M H$, Chourasia $H R$, Jabali $A H$, Bajawi $H A$, Jamal $\mathrm{H}$, Testarelli $\mathrm{L}$, et al. C-shaped canal configuration in mandibular premolars and molars: Prevalence, correlation, and differences: An in vivo study using cone-beam computed tomography. Niger J Clin Pract 2020;23:232-9.

54. von Arx T, Janner SF, Hanni S, Bornstein MM. Evaluation of New Cone-beam Computed Tomographic Criteria for Radiographic Healing Evaluation after Apical Surgery: Assessment of Repeatability and Reproducibility. J Endod 2016;42:236-42. 
55. Balto HA, Alabdulaaly L, Bahammam S, Al-Ekrish AA. Comparative analysis of prevalence of apical periodontitis in smokers and nonsmokers using cone-beam computed tomography. Saudi Dent J 2019;31:52-7.

56. Abella F, Patel S, Duran-Sindreu F, Mercade M, Bueno R, Roig M. Evaluating the periapical status of teeth with irreversible pulpitis by using cone-beam computed tomography scanning and periapical radiographs. J Endod 2012;38:1588-91

57. Kruse C, Spin-Neto R, Evar Kraft DC, Vaeth M, Kirkevang LL. Diagnostic accuracy of cone beam computed tomography used for assessment of apical periodontitis: an ex vivo histopathological study on human cadavers. Int Endod J 2019;52:439-50.

58. Restrepo-Restrepo FA, Canas-Jimenez SJ, Romero-Albarracin RD, Villa-Machado PA, Perez-Cano MI, Tobon-Arroyave SI. Prognosis of root canal treatment in teeth with preoperative apical periodontitis: a study with cone-beam computed tomography and digital periapical radiography. Int Endod J 2019;52:1533-46.

59. Mashyakhy M, Chourasia HR, Halboub E, Roges RA, Gambarini G. Nonsurgical Management and 2-year Follow-up by means of Cone Beam Computed Tomography of an Invasive Cervical Resorption in a Molar. J Contemp Dent Pract 2018;19:1152-6.

60. de Freitas JC, Lyra OC, de Alencar AH, Estrela C. Long-term evaluation of apical root resorption after orthodontic treatment using periapical radiography and cone beam computed tomography. Dental Press J Orthod 2013;18:104-12.

61. Liang YH, Li G, Shemesh H, Wesselink PR, Wu MK. The association between complete absence of post-treatment periapical lesion and quality of root canal filling. Clin Oral Investig 2012;16:1619-26.

62. Nascimento EHL, Gaeta-Araujo $H$, Andrade MFS, Freitas DQ. Prevalence of technical errors and periapical lesions in a sample of endodontically treated teeth: a CBCT analysis. Clin Oral Investig 2018;22:2495-503.

63. Gambarini G, Piasecki L, Miccoli G, Gaimari G, Nardo DD, Testarelli L. Cone-beam computed tomography in the assessment of periapical lesions in endodontically treated teeth. Eur J Dent 2018;12:136-43.

64. Egger M, Schneider M, Davey Smith G. Spurious precision? Metaanalysis of observational studies. BMJ 1998;316:140-4.

65. Stroup DF, Berlin JA, Morton SC, Olkin I, Williamson GD, Rennie $D$, et al. Meta-analysis of observational studies in epidemiology: a proposal for reporting. Meta-analysis Of Observational Studies in Epidemiology (MOOSE) group. JAMA 2000;283:2008-12.

66. Hirschfeld Z, Sela J, Ulmansky M. Hydrex and its effect on the pulp. Preliminary findings on the rat molar. Oral Surg Oral Med Oral Pathol 1972;34:364-71.

67. Ricucci D, Lin LM, Spangberg LS. Wound healing of apical tissues after root canal therapy: a long-term clinical, radiographic, and histopathologic observation study. Oral Surg Oral Med Oral Pathol Oral Radiol Endod 2009;108:609-21.

68. Ricucci D, Siqueira JF, Jr. Biofilms and apical periodontitis: study of prevalence and association with clinical and histopathologic findings. J Endod 2010;36:1277-88.

69. Orstavik D, Kerekes K, Eriksen HM. The periapical index: a scoring system for radiographic assessment of apical periodontitis. Endod Dent Traumatol 1986;2:20-34.

70. Akgöz S, Ercan I, İsmet K. Meta-analizi. Uludağ Üniversitesi Tıp Fakültesi Dergisi 2004;30:107-12.

\section{The effect of the quality of coronal restoration versus the quality of root canal filling on periapical health: systematic review and meta- analysis}

\section{ABSTRACT}

OBJECTIVE: The aim of this meta-analysis was to compare the impact of the quality of root canal treatment versus the quality of coronal restoration on periapical health.

Materials and Method: A literature review was conducted using the search terms "endodontics", "periapical index", "periapical status", "quality of root canal treatment", "root treatment", "root canal treatment", "coronal restoration", "quality of root canal treatment", "cone beam computed tomography", and "restoration". The studies evaluating the effect of the quality of root canal filling and the quality of coronal restoration on periapical tissues were selected. Data were collected by two researchers according to the inclusion and exclusion criteria. The ratio of teeth with apical periodontitis was recorded for each category: adequate root canal treatment (AC), inadequate root canal treatment (IC), adequate restoration (AR), and inadequate restoration (IR). The data were analyzed using meta-analysis for odds ratios. The significance level was set at $\alpha=0.05$.

RESULTS: There were statistically significant differences between AC-IR and AC-AR [ $p=0.02$ and $O R=1.88,95 \%$ confidence interval (CI): 1.13-3.13], between IC-AR and AC-AR $[p=0.006$ and $O R=3.23(1.41-7.39)]$, between IC-IR and ACAR $[p<0.00001$ and OR=5.18 (2.62-10.23)], between IC-AR and $A C-I R$ [ $p=0.02$ and $O R=1.48(1.07-2.03)]$, between ICIR and $A C$-IR $[p<0.0001$ and $O R=2.44(1.69-3.51)]$, between IC-IR and IC-AR [p<0.00001 and OR=1.80 (1.38-2.34)]

ConcLusion: On the basis of the current best available evidence, the odds for the healing of apical periodontitis increases with both adequate root canal treatment and adequate restorative treatment. When AC-IR versus IC-AR was evaluated, it was revealed that root canal filling was more important than coronal restoration.

KEYWORDS: Cone beam computed tomography, periapical index, periapical status, quality of root canal treatment, quality of coronal restoration 